\section{Seed Germination of Annual Vinca Responds to Irradiation and Temperature}

\author{
Frank A. Blazich \\ Department of Horticultural Science, North Carolina State University, Raleigh, \\ NC 27695-7609
}

\author{
Paul H. Henry \\ Department of Plant and Soil Science, Southern Illinois University, Carbondale, \\ IL 62901-4415
}

\author{
Farrell C. Wise \\ Westvaco Corporation, Box 1950, Summerville, SC 29484
}

Additional index words. Catharanthus roseus, bedding plant, daily degree hours, heat input, photoperiod, sexual propagation, temperature cycle

\begin{abstract}
Seeds of 'Dawn Carpet' and 'Little Bright Eye' annual vinca [Catharanthus roseus (L.) G. Don] were subjected to 32 treatments, arranged as a four $\times$ four $\times$ two factorial. For each cultivar, seeds were exposed to one of four temperatures $(15,20,25$, or 30C) during the 8-hour (day) and 16-hour (night) portions of the cycle. Within each temperature regime, half the seeds of each cultivar were irradiated for 1 hour daily, and the other half remained in constant darkness. Final germination percentages were suppressed at $15 \mathrm{C}$ day or night temperatures; at temperatures $\geq 20 \mathrm{C}$, there were no significant differences between treatments. Heat input (daily degree hours) was a controlling factor in germination; different temperature cycles with equivalent numbers of daily degree hours had similar effects on germination response. There was a strong interaction between temperature and irradiation regime for both cultivars. Irradiating seeds for 1 hour/day reduced final germination percentages under cool (15C) conditions; response was not adversely affected when seeds at $15 \mathrm{C}$ were germinated in darkness. In a second experiment, seeds at $25 \mathrm{C}$ were exposed to daily photoperiods of $0,1,2,4,8,12$, or 24 hours. Germination percentages obtained in darkness and at photoperiods $\leq 12$ hours were equivalent. Twenty-four-hour photoperiods suppressed germination compared to all other irradiation treatments.
\end{abstract}

Annual vinca is a popular bedding plant notable for continuous flower production from spring to frost. The species tolerates heat, drought, wind, and poor soils, making it a garden mainstay in the southern United States, the coastal regions, and the Central Valley of California. It would help annual vinca growers if the time required to produce a salable plant (10 to 14 weeks) could be shortened through more efficient propagation techniques. The species is propagated by seed, and recommendations found in the literature regarding germination are contradictory.

Propagation guidelines for the species typically recommend germinating seeds at 21 to

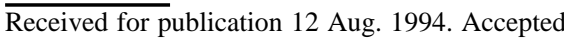
for publication 13 Sept. 1994. This research was funded in part by the North Carolina Agricultural Research Service (NCARS), Raleigh. Use of trade names in this publication does not imply endorsement by the NCARS of products named nor criticism of similar ones not mentioned. Assistance of the staff of the Southeastern Plant Environment Laboratory (Phytotron) is gratefully acknowledged. The cost of publishing this paper was defrayed in part by the payment of page charges. Under postal regulations, this paper therefore must be hereby marked advertisement solely to indicate this fact.
27C in darkness (Bedding Plants Inc., 1986; Cathey, 1976; Nau, 1991; Reilly, 1978). However, the Association of Official Seed Analysts (1981) recommends germination at a 8/ 16-h thermoperiod of $30 / 20 \mathrm{C}$, with 8 -h irradiation daily during the high-temperature portion of the cycle. In what we consider to be the most thorough study to date, Carpenter and Boucher (1992) reported that germination was optimized at 25 to $30 \mathrm{C}$ and that constant irradiation inhibited germination. However, their study did not investigate the effect of alternating temperatures or photoperiods $<24 \mathrm{~h}$.

Several years ago, we conducted some experiments to investigate the influence of irradiation and temperature on annual vinca germination. In this article, we present results of these studies, which complement the work of Carpenter and Boucher (1992).

\section{Materials and Methods}

General procedures. Two experiments were conducted. Experiment 1 determined the optimum temperature for germination with and without a daily 1 -h irradiation treatment. Experiment 2 examined the influence of photoperiod when seeds were germinated at a constant temperature.
Seeds of 'Dawn Carpet' and 'Little Bright Eye' annual vinca were obtained in July 1987 from H.G. German Seeds, Smethport, Pa., and were stored in darkness at 4C. Label information for 'Dawn Carpet' (flower color, pink with a rose center) and 'Little Bright Eye' (flower color, white with a red center) indicated $85 \%$ germination when tested in Jan. 1987 and Dec. 1986, respectively.

We germinated seeds in $9-\mathrm{cm}$, covered, glass petri dishes containing prewashed blotters moistened with tap water. Blotters were kept moist throughout experiments, and seeds exhibiting signs of disease or decay were removed from dishes immediately. Dark-treated seeds remained in double-layer, black sateen cloth bags throughout the experiments, and all watering and germination counts were performed in a darkroom equipped with a fluorescent lamp covered with a green acetate filter (Rosco Laboratories, Port Chester, N.Y.). Photoperiod treatments were imposed by seed removal and placement in black cloth bags. Seeds were exposed to constant irradiation in the 24-h photoperiod treatment.

In both experiments, the design was completely randomized with four replications per treatment. A replication consisted of a petri dish containing 100 seeds. Seeds were considered germinated when the emerging radicle was $\geq 2 \mathrm{~mm}$ long.

Optimum germination temperature (Expt. 1). In Aug. 1987, seeds of 'Dawn Carpet' and 'Little Bright Eye' were removed from storage and sown in petri dishes. Following sowing, all dishes were placed in black cloth bags, randomized on metal trays, and placed in seed germinators (J.P. Pfeiffer \& Son, Baltimore) maintained within $\pm 1 \mathrm{C}$ of the set point.

There were 32 treatments, arranged as a four $\times$ four $\times$ two factorial. For each cultivar, seeds were exposed to one of four temperatures $(15,20,25$, or 30C) during the 8 -h (day) and 16-h (night) portions of the cycle. Within each temperature regime, four dishes of seeds were irradiated daily for $1 \mathrm{~h}$ during the final hour of the 8-h portion of the cycle; four dishes remained in constant darkness. Irradiation treatments were imposed by setting trays on benches adjacent to the germinators and removing dishes from the black cloth bags. Cool-white fluorescent lamps provided a photosynthetic photon flux (PPF) (400 to $700 \mathrm{~nm}$ ) of 24 $\mu \mathrm{mol} \cdot \mathrm{m}^{-2} \cdot \mathrm{s}^{-1}$ as measured at dish level with a quantum-radiometer-photometer (model LI185; LI-COR, Lincoln, Neb.).

Germination counts were recorded every 2 days for 10 days. Response was examined as a function of day and night temperatures (DT and NT, respectively) and daily heat input. Daily degree hours (ddh) were calculated for each of the 16 cycles as follows: $(8 \times$ shortperiod temperature $)+(16 \times$ long-period temperature). This approach previously has been used to describe the effect of alternating temperatures on seed germination (Adkins et al., 1984) and seedling growth (Hellmers, 1962).

Data for both cultivars were subjected to analysis of variance (ANOVA) (SAS Institute, 1990). Several cycles converted to an equivalent number of $\mathrm{ddh}\left(\right.$ in ${ }^{\circ} \mathrm{C}, \mathrm{ddh}$ ) $[15 / 20$ 
and $25 / 15=440,20 / 20$ and $30 / 15=480,25 / 20$ and $15 / 25=520,30 / 20$ and $20 / 25=560,15 / 30$ and $25 / 25=600,30 / 25$ and $20 / 30=640$. In these instances, the cycles with an equivalent number of ddh did not differ significantly in their effect on germination response. Therefore, treatment means for 440 to $640 \mathrm{ddh}$ were averaged over two cycles and analyzed as having eight replications; treatment means for $360,400,680$, and 720 ddh were based on a single cycle with four replications.

Arcsin transformation of data did not improve the precision with which treatment differences could be detected. Therefore, only nontransformed data are presented.

Influence of photoperiod (Expt. 2). In Sept. 1987, seeds of both cultivars were removed from storage and sown in petri dishes. Dishes were placed in a growth room maintained at 25 $\pm 1 \mathrm{C}$ and exposed to daily photoperiods of 0 , $1,2,4,8,12$, or $24 \mathrm{~h}$. We chose $25 \mathrm{C}$ because data from Expt. 1 indicated that 600 ddh was sufficient to maximize cumulative germination. The growth room was equipped with cool-white fluorescent lamps that provided a $\mathrm{PPF}$ of $65 \mu \mathrm{mol} \cdot \mathrm{m}^{-2} \cdot \mathrm{s}^{-1}$ as measured at dish level with the same instrument used in Expt. 1. Germination counts were recorded daily for 5 days. Data for each cultivar were subjected to ANOVA (SAS Institute, 1990) to determine the influence of irradiation treatments on germination response.

\section{Results}

Optimum germination temperature (Expt. 1). DT and NT had a significant effect on final germination percentages of both cultivars (Table 1). The interaction between DT and NT temperatures was also significant. Final germination percentages were reduced when a DT of $15 \mathrm{C}$ was combined with either a 15 or $20 \mathrm{C}$ NT (data not presented). At DT $\geq 20 \mathrm{C}$, there were no longer significant interactions with NT for either cultivar.

Irradiation regime also affected germination response of both cultivars (Table 1). Averaged over DT and NT, final germination percentages of irradiated seeds were $81 \%$ ('Dawn Carpet') and 94\% ('Little Bright Eye'), compared to 94\% ('Dawn Carpet') and 97\% ('Little Bright Eye') for seeds maintained in darkness. The effect of irradiation varied with germination temperature, as indicated by significant interactions between these factors (Table 1). Irradiation reduced final germination of seeds at low (15C) DT and NT (Fig. 1). Inhibition was greater when $15 \mathrm{C}$ was at night (Fig. $1 \mathrm{~B}$ and D) than during the day (Fig. $1 \mathrm{~A}$ and $\mathrm{C}$ ) and was likely due to the extended length of time ( 8 vs. $16 \mathrm{~h}$ ) that seeds were subjected to $15 \mathrm{C}$. When nonirradiated seeds were analyzed as a separate dataset, neither DT nor NT had a significant effect on the final germination percentage of either cultivar.

The number of ddh to which seeds were exposed also had a significant effect on final germination percentages (Table 2). However, response to ddh depended on the irradiation regime to which seeds had been subjected (Fig. 2 A and B). For seeds maintained in darkness, germination percentages were not affected by ddh and averaged $86 \%$ for 'Dawn Carpet' and 97\% for 'Little Bright Eye'. Irradiating seeds inhibited germination when heat inputs were $<440$ ddh (Fig. 2 A and B); response of irradiated and nonirradiated seeds was similar when exposed to a ddh $\geq 440$.

For both cultivars, germination rate increased most rapidly as ddh increased from 360 to 400 (data not presented). At ddh $\geq 440$, the germination rate continued to increase, but final germination percentages after 10 days were not affected.

At 720 ddh, germination of both cultivars was essentially complete after 4 days.

Influence of photoperiod (Expt. 2). When maintained at a constant $25 \mathrm{C}$ (600 ddh), germination percentages were equivalent for seeds exposed to photoperiod $\leq 12 \mathrm{~h}$ and those maintained in darkness (Table 3). A 24-h photoperiod significantly $(P \leq 0.01)$ reduced germination compared to the other irradiation exposures. Constant irradiation inhibited germination of both cultivars similarly.

\section{Discussion}

Our results indicate a need to modify recommendations concerning annual vinca germination. Carpenter and Boucher (1992) reported that constant temperatures $<25 \mathrm{C}(600$ $\mathrm{ddh}$ ) reduced the germination rate and the final germination percentages of annual vinca seeds maintained in darkness. Our results indicate that the germination rate increases with heat input, but that final germination percentages

Table 1. Influence of day temperature (DT), night temperature (NT), and irradiation (I) on seed germination of 'Dawn Carpet' and 'Little Bright Eye' annual vinca.

\begin{tabular}{|c|c|c|c|c|c|c|c|c|c|}
\hline \multirow[b]{4}{*}{ Day temp $\left({ }^{\circ} \mathrm{C}\right)^{\mathrm{y}}$} & \multirow[b]{4}{*}{ Light } & \multicolumn{8}{|c|}{ Final germination $(\%)$} \\
\hline & & \multicolumn{3}{|c|}{ Dawn Carpet } & & \multicolumn{4}{|c|}{ Little Bright Eye } \\
\hline & & \multicolumn{8}{|c|}{ Night temp ${ }^{\mathrm{z}}\left({ }^{\circ} \mathrm{C}\right)$} \\
\hline & & 15 & 20 & 25 & 30 & 15 & 20 & 25 & 30 \\
\hline \multirow[t]{2}{*}{15} & $-{ }^{x}$ & 83 & 85 & 89 & 85 & 96 & 98 & 95 & 96 \\
\hline & $+^{\mathrm{w}}$ & 23 & 88 & 86 & 89 & 65 & 95 & 98 & 96 \\
\hline \multirow[t]{2}{*}{20} & - & 86 & 88 & 81 & 89 & 98 & 97 & 98 & 99 \\
\hline & + & 62 & 85 & 82 & 91 & 85 & 98 & 96 & 97 \\
\hline \multirow[t]{2}{*}{25} & - & 84 & 88 & 83 & 85 & 98 & 98 & 97 & 92 \\
\hline & + & 81 & 88 & 89 & 84 & 93 & 98 & 95 & 96 \\
\hline \multirow[t]{2}{*}{30} & - & 86 & 88 & 89 & 85 & 97 & 97 & 97 & 95 \\
\hline & + & 84 & 87 & 87 & 86 & 94 & 96 & 99 & 97 \\
\hline \multicolumn{10}{|l|}{ Significance } \\
\hline DT & & \multicolumn{4}{|c|}{$*$} & \multicolumn{4}{|c|}{$*$} \\
\hline NT & & \multicolumn{4}{|c|}{$* *$} & \multicolumn{4}{|c|}{$*$} \\
\hline I & & \multicolumn{4}{|c|}{$* *$} & \multicolumn{4}{|c|}{$*$} \\
\hline $\mathrm{DT} \times \mathrm{NT}$ & & \multicolumn{4}{|c|}{$* *$} & \multicolumn{4}{|c|}{$* *$} \\
\hline $\mathrm{DT} \times \mathrm{I}$ & & \multicolumn{4}{|c|}{$* *$} & \multicolumn{4}{|c|}{$*$} \\
\hline $\mathrm{NT} \times \mathrm{I}$ & & \multicolumn{4}{|c|}{$* *$} & \multicolumn{4}{|c|}{$* *$} \\
\hline
\end{tabular}

${ }^{\mathrm{z}}$ Refers to 16-h (night) portion of cycle.

${ }^{y}$ Refers to 8-h (day) portion of cycle.

${ }^{x}$ Seeds germinated in darkness throughout the 8- and 16-h portions of the cycle.

${ }^{\text {w }}$ Seeds received $1-\mathrm{h}$ irradiation during the final hour of the $8-\mathrm{h}$ portion of the cycle.

*,**Significant at $P \leq 0.05$ or 0.01 , respectively.

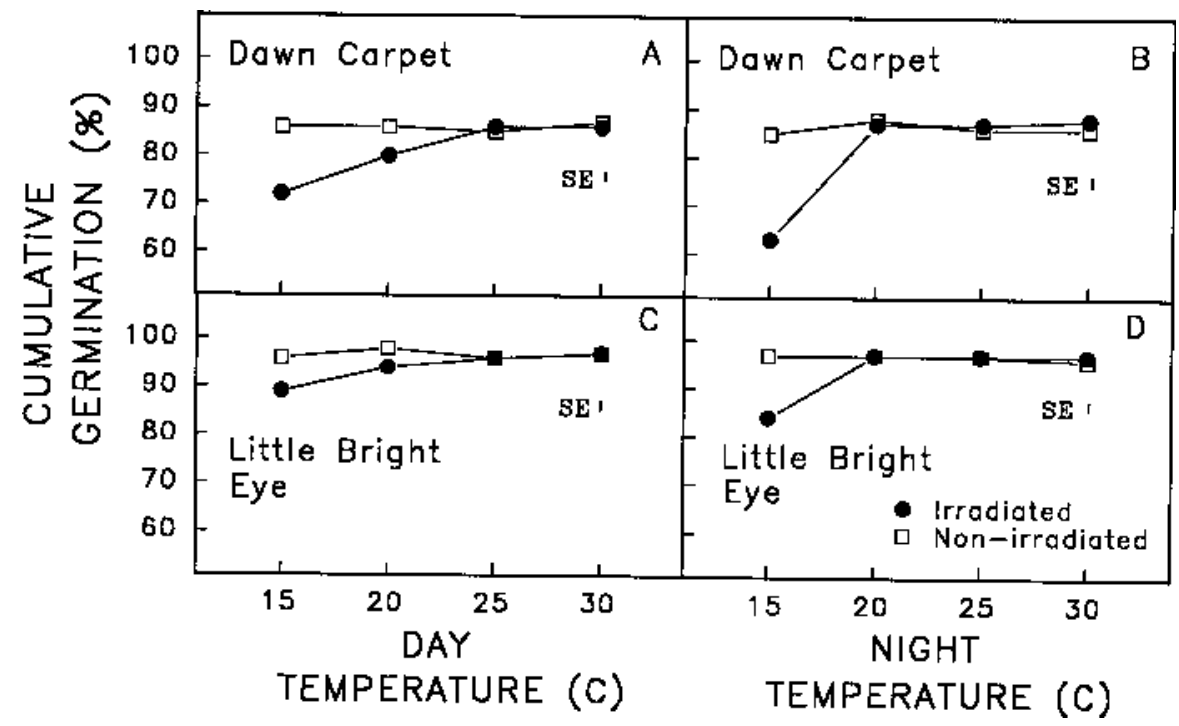

Fig. 1. Effect of day temperature, night temperature, and irradiation on cumulative seed germination percentages of $(\mathbf{A}, \mathbf{B})$ 'Dawn Carpet' and $(\mathbf{C}, \mathbf{D})$ 'Little Bright Eye' annual vinca. Irradiated seeds received a daily 1 -h exposure of light during the final hour of the 8 -h portion of the temperature cycle. Legend in (D) applies to all graphs. 
Table 2. Influence of daily heat input expressed as daily degree hours (ddh) and irradiation (I) on seed germination of 'Dawn Carpet' and 'Little Bright Eye' annual vinca.

\begin{tabular}{|c|c|c|c|c|c|}
\hline \multirow{3}{*}{$\begin{array}{l}\text { Daily heat } \\
\text { input } \\
\text { (ddh) }\end{array}$} & \multirow{3}{*}{$\begin{array}{l}\text { Temp } \\
\text { cycle } \\
\left({ }^{\circ} \mathrm{C}\right)\end{array}$} & \multicolumn{4}{|c|}{ Final germination (\%) } \\
\hline & & \multicolumn{2}{|c|}{$\begin{array}{l}\text { Dawn } \\
\text { Carpet }\end{array}$} & \multicolumn{2}{|c|}{$\begin{array}{c}\text { Little } \\
\text { Bright Eye }\end{array}$} \\
\hline & & $\overline{\text { Dark }^{2}}$ & Light $^{y}$ & Dark & Light \\
\hline 360 & $15 / 15$ & 83 & 23 & 96 & 65 \\
\hline 400 & $20 / 15$ & 86 & 62 & 98 & 85 \\
\hline \multirow[t]{2}{*}{$440^{x}$} & $15 / 20$ & 85 & 88 & 98 & 95 \\
\hline & $25 / 15$ & 84 & 81 & 98 & 93 \\
\hline \multirow[t]{2}{*}{480} & $20 / 20$ & 88 & 85 & 97 & 98 \\
\hline & $30 / 15$ & 86 & 84 & 97 & 94 \\
\hline \multirow[t]{2}{*}{520} & $25 / 20$ & 88 & 88 & 98 & 98 \\
\hline & $15 / 25$ & 89 & 86 & 95 & 98 \\
\hline \multirow[t]{2}{*}{560} & $30 / 20$ & 87 & 87 & 97 & 96 \\
\hline & $20 / 25$ & 82 & 82 & 98 & 96 \\
\hline \multirow[t]{2}{*}{600} & $15 / 30$ & 85 & 89 & 96 & 96 \\
\hline & $25 / 25$ & 83 & 89 & 97 & 95 \\
\hline \multirow[t]{2}{*}{640} & $30 / 25$ & 89 & 87 & 97 & 99 \\
\hline & $20 / 30$ & 89 & 91 & 99 & 97 \\
\hline 680 & $25 / 30$ & 85 & 84 & 92 & 96 \\
\hline 720 & $30 / 30$ & 85 & 86 & 95 & 97 \\
\hline \multicolumn{6}{|c|}{ Significance } \\
\hline ddh & & \multicolumn{2}{|c|}{$* *$} & \multicolumn{2}{|c|}{$* *$} \\
\hline I & & \multicolumn{2}{|c|}{$* *$} & \multicolumn{2}{|c|}{$*$} \\
\hline $\operatorname{ddh} \times I$ & & \multicolumn{2}{|c|}{$* *$} & \multicolumn{2}{|c|}{$* *$} \\
\hline
\end{tabular}

${ }^{2}$ Seeds germinated in darkness throughout both portions of the cycle.

${ }^{y}$ Seeds received 1-h irradiation during the final hour of the 8-h portion of the cycle.

${ }^{x}$ Treatment mean averaged over cycles and used in analysis of variance.

${ }^{*}, *$ Significant at $P \leq 0.05$ or 0.01 , respectively.

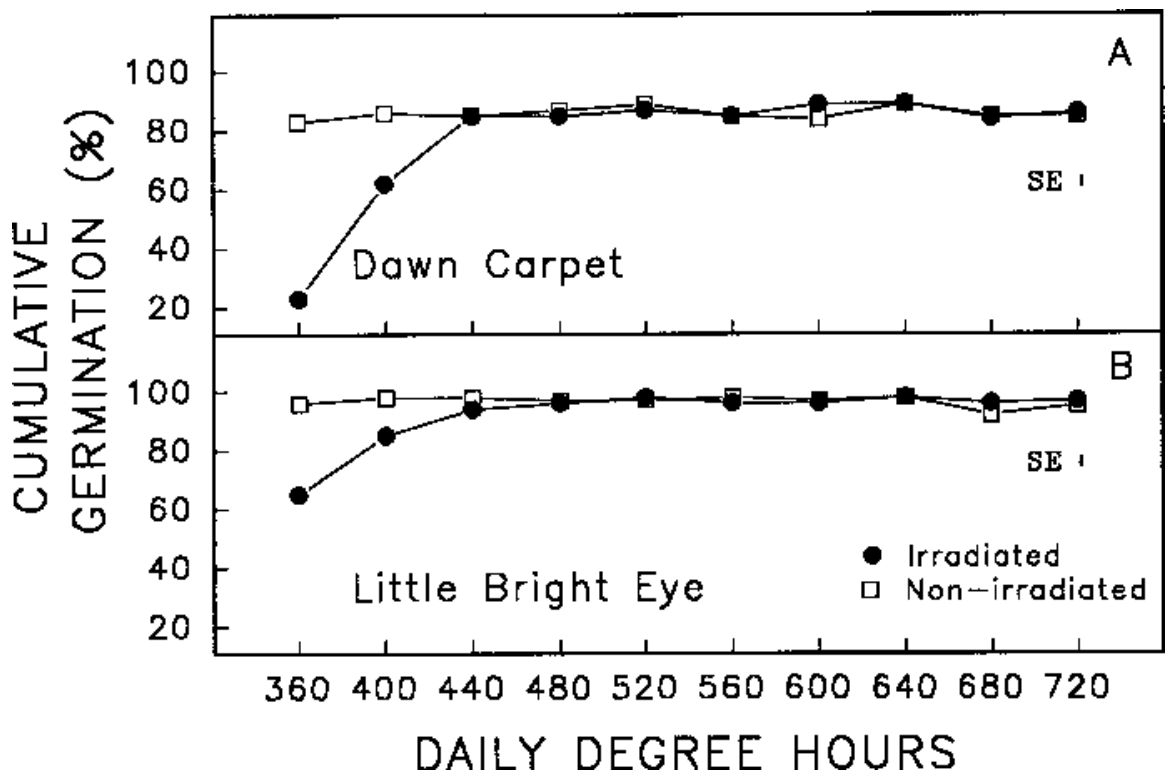

Fig. 2. Effect of daily heat input, expressed as daily degree hours, and irradiation on cumulative seed germination percentages of (A) 'Dawn Carpet' and (B) 'Little Bright Eye' annual vinca. Irradiated seeds received a daily 1-h exposure of light during the final hour of the 8-h portion of the temperature cycle.

are maximized as long as daily heat input is $\geq 480 \mathrm{ddh}$. Contrasting results may be due to the different cultivars used in the two studies.

Carpenter and Boucher (1992) also reported that germination percentages at $25 \mathrm{C}$ were reduced significantly when seeds were exposed to 24-h photoperiods rather than maintained in
Table 3. Influence of photoperiod on cumulative seed germination of 'Dawn Carpet' and 'Little Bright Eye' annual vinca.

\begin{tabular}{lcc}
\hline \hline & \multicolumn{2}{c}{$\begin{array}{c}\text { Cumulative germination } \\
\text { (\%) }\end{array}$} \\
\cline { 2 - 3 } $\begin{array}{l}\text { Photoperiod } \\
\text { (h) }\end{array}$ & $\begin{array}{c}\text { Dawn } \\
\text { Carpet }\end{array}$ & $\begin{array}{c}\text { Little } \\
\text { Bright Eye }\end{array}$ \\
\hline 0 & 85 & 97 \\
1 & 85 & 98 \\
2 & 86 & 95 \\
4 & 87 & 94 \\
8 & 82 & 95 \\
12 & 82 & 93 \\
24 & 62 & 67 \\
Significance & & \\
$\quad$ Linear & NS & NS \\
Quadratic & $* *$ & $* *$ \\
\hline
\end{tabular}

${ }^{2}$ Seeds germinated at $25 \mathrm{C}$.

Ns, ** Nonsignificant or significant at $P \leq 0.01$, respectively.

$\leq 12 \mathrm{~h}$ do not adversely affect the response compared to seeds maintained in darkness. Thus, the irradiation duration, rather than its presence or absence, is apparently the critical factor influencing germination.

Carpenter and Boucher (1992) conducted separate studies on the effects of temperature and irradiation and were unable to investigate the interaction between these factors. We have demonstrated the significance of this interaction. When seeds are maintained in darkness, final germination percentages are similar at any daily heat input within the range of 360 to $720 \mathrm{ddh}$. If seeds are irradiated for $1 \mathrm{~h} / \mathrm{day}$, heat inputs should be $\geq 440 \mathrm{ddh}$ to ensure maximum germination.

\section{Literature Cited}

Adkins, C.R., L.E. Hinesley, and F.A. Blazich 1984. Role of stratification, temperature, and light in Fraser fir germination. Can. J. For. Res. 14:88-93.

Association of Official Seed Analysts. 1981. Rules for testing seeds. J. Seed Technol. 6(2):1-125.

Bedding Plants Inc. 1986. Vinca-A tough beauty. BPI News 17(12):6.

Carpenter, W.J. and J.F. Boucher. 1992. Germination and storage of vinca seed is influenced by light, temperature, and relative humidity. HortScience 27:993-996.

Cathey, H.M. 1976. Seed germination, p. 47-54. In: J.W. Mastalerz (ed.). Bedding plants: A manual on the culture of bedding plants as a greenhouse crop. 2nd ed. Pennsylvania Flower Growers, University Park, Pa.

Hellmers, H. 1962. Temperature effect on optimum tree growth, p. 275-288. In: T.T. Kozlowski (ed.). Tree growth. Ronald Press, New York.

Nau, J. 1991. Vinca, p. 782-784. In: V. Ball (ed.) Ball red book: Greenhouse growing. 15th ed. Geo. J. Ball Publishing, West Chicago, Ill.

Reilly, A. 1978. Park's success with seeds. Geo. W. Park Seed Co., Greenwood, S.C.

SAS Institute. 1990. SAS/STAT user's guide. vol. 1. SAS Institute, Cary, N.C. 